\title{
Screening for Enzymatic Production Ability and Antimicrobial Activity of Actinomycetes Isolated from Soil in Hillah/Iraq
}

\author{
*Eman Mohammed Jaralla ${ }^{1} *$ Nebras N. Al-Dabbagh, ${ }^{*}$ NooraM.Hameed \\ **Noora Abdul -Hussain \\ *University of Babylon/College of Science /Dept. of Biology \\ **University of Babylon/College of Dentistry \\ ${ }^{1}$ Jarallaheman@Gmail.com
}

\begin{abstract}
Forty soil samples collected from different sites of Hillah city /Iraq.Sixty seven Streptomyces isolates were obtained, purified and identified according to morphological properties and biochemical tests. All of these isolates were screened fortheir antimicrobial activity, in addition to production of some important enzymes such as amylase, protease, cellulase and L-asparaginase.The results exhibited that five isolates; Streptomyces sp.(SA.2 ,SK.5 , SM.42, SS.50 and SI.63) have such potential. The most active isolate in production of thestudied enzymes was SM.48.On the other hand, it has less antibacterial activity againsttestmicroorganismsEscherichia coli ,Pseudomonas aeruginosa,Staphylococcusaureus ,Moganella sp. and Klebseillapnumoniae. While the isolate Streptomyces sp.SS.50 has no activity in enzyme production, but it has a good antibacterial activity due to inhibition zone diameter (mm);19,18,16,14 and $16 \mathrm{~mm}$ towards the previous mentioned bacterial species, respectively, in addition to that, it also gave clear zone at 16 and 12 mmagainst Candida albicans and Candida glabrata, respectively.
\end{abstract}

\section{Introduction}

Actinomycetes are classified as vast group of gram positive bacteria which have filamentous appearance and widely present in both terrestrial and aquatic environments. Streptomycetes are the major class of soil actinomycetes that produce numerous natural metabolites such as antibiotics and enzymes (Chianiet al., $\underline{2010)}$.

They produce several enzymes, degrading complex organic materials in soil or sediments such as protease, cellulases, amylase, gelatinase, lectinases and ureases (Gluve and Desmukh, 2012).

Amylase is one of the commonly used enzymes in different starch industries. It has many industrial applications in the production of syrup made from oligosaccharide and monosaccharide. In textile industries, amylase enzyme is used for resizing of clothing materials (Tonkova, 2006). Actinomycetes are good decomposers of organis materials and Production of amylases was reported by some strains of actinomycetes (Kar and Ray, 2008).

Actinomycetecellulases are inducible extracellular enzymes (Ibrahim and El-diwany, 2007) that can be produced during their growth on cellulosic materials. Thus, introduction of cellulolytic microorganisms is a beneficial microbiological tool for recovery of bioenergy from degraded cellulose (Balamuruganet al., 2011) and have gained significant attention due to their wide applicability in various industrial processes including pulp and paper, textile, laundry, biofuel production, food and feed industry, brewing and agriculture (Kuhadet al., 2011).

cellulase enzymes are involved in enzymatic hydrolysis of cellulose, one of the most abundant organic materials that can be converted to products with significant commercial interest. Bioconversion of cellulose to monomeric sugars has been intensively studied as re-searchers seek to produce bioethanol and bio-based products, food and animal feeds, and many valuable chemicals (Barros et al., 2010).

In addition to cellulases, streptomycetes have the ability to produce L-asparaginases that used for the treatment of malignancies of the multiorgans (Kumar and Selvam, 2011). Also it used widely as a therapeutic agent for treating acute lymphoblastic leukemia in children and lympho-sarcoma (Khamnaet al., 2009). The search for L-asparaginase sources, like actinomycetes, can lead to an enzyme with less adverse effects. Actinomycetes represent a good source for the production of L-asparaginase (Savitri and Azmi, 2003).

One of the most important groups of enzymes that produced commercially and for industrial purposes are Proteases (Deng et al., 2010). They have extensive applications in a range of industrial products and processes including detergents, food, pharmaceuticals and leather(Ribitschaet al., 2010). In spite of considering Actinomycetes to be among the most important producers of antibiotics (Avithaet al., 2010), However, the present knowledge concerning proteases of actinomycetes to be the most important group of secondary metabolites that are widely exploited (Limkhadaet al., 2010). This study aimed to isolate various 
Streptomycetesspecies from agricultural soils in Hillah city and screening it for their potential to produce some hydrolytic enzymes (cellulase, amylase, protease and L- asparaginase).

\section{Materials and Methods:}

Samples Collection: The agricultural soil samples were collected from different sites in Hillah city/Iraq. These samples were transferred to the laboratory by sterile dried polyethylene containers and kept at room temperature until used.

Isolation of Actinomycetes: Soil samples were treated with caliseum carbonate for $24 \mathrm{~h}$, then subjected to serial dilution till $10^{-6}$. One milliliter of each dilution cultured on ISP2 media by pour plate method (Collins etal.,1995).The plates were incubated at $28 \mathrm{C}^{\circ}$ for 7 days. The colonies were subcultured several times on the same media to get pure isolated colonies.

\section{Yeast extract-malt extract agar(ISP-2) (Pridhamet al., 1957)}

This media was used for growing Actinomycetes isolates. It prepared from the following chemicals :Bacto-Yeast Extract $4.0 \mathrm{~g}$,Bacto-Malt Extract $10.0 \mathrm{~g}$,Bacto-Dextrose $4.0 \mathrm{~g}$, Distilled water $1.0 \mathrm{Liter}$, then addagar- agar 20.0 g.Adjust $\mathrm{pH}$ to 7.3. Liquefy agar by steaming at $100^{\circ} \mathrm{C}$ for $15-20$ minutes. Then sterilize by autoclaving at $121^{\circ} \mathrm{C}$, for 15 minute.

\section{Screening of Actinomycetes for enzyme production:}

1-Amylase Production:Theisolateswere cultured onsterile starch media for 5 days at $28 \mathrm{Co}$, then it tested for amylase production by flooding bacterial growth by iodine solution. The positive result represented by appearance of clear zone around the isolates surrounding by purple background .

2- Cellulase production: The isolated Actinomycetes were grown for 4 days on CMC agar which composed of the following components :carboxymethyl cellulose $10 \mathrm{~g}, \mathrm{~K} 2 \mathrm{HPO} 410 \mathrm{~g}, \mathrm{MgSO} 410 \mathrm{~g}, 0.03 \mathrm{NaCl},(\mathrm{NH} 4) 2 \mathrm{SO} 4$ $2 \mathrm{~g}, \mathrm{FeSO} 40.1 \mathrm{mg}$ and $20 \mathrm{~g}$ of agar -agar. After incubation period, $1 \mathrm{ml}$ of $5 \%$ iodine solution together with 1 $\mathrm{ml}$ of mercuric iodine was covered the colonies .Clear yellow zone around the growth refer to positive result.

3-Protease Production :Actinomycetesisolates were grown on skim milk media which consist of skim milk powder $10 \mathrm{~g}$,pepton $5 \mathrm{~g}, \mathrm{NaCl} 0.03 \mathrm{~g}$ and agar $20 \mathrm{~g}$. These component were dissolved in 1 liter of distilled water ,then pHwas adjusted to 7.0 . The plates were streaked by isolates and incubated at 28 Co for 4 days. The formation of clear zonearoundActinomycetes colonies represented positive results(Kavyaet al., 2012 ).

4-L- Asparaginase Production : Asparaginase - glucose agar media were inoculated by Actinomycetes isolates .This media constructed by glucose $1 \mathrm{~g}$, yeast extract $2 \mathrm{~g}$, L-asparaginase $10 \mathrm{~g}, \mathrm{~K} 2 \mathrm{HPO} 40.5 \mathrm{~g}, \mathrm{NaCl} 0.03 \mathrm{~g}$, phenol red 3-4 drop, and agar $20 \mathrm{~g}$, distilled water $1 \mathrm{~L}$,adjust the final $\mathrm{pH}$ to 7.0 .

Combine all ingredients except glucose. Autoclave at $121 \mathrm{C}$

for 15 minutes. Aseptically add filter-sterilized glucose solution to

the medium. The positive result represented by changing the yellow color of media to pink color, in addition to formation of clear zone surrounding producing colonies (Kavyaet al., 2012).

Antimicrobial activity assay : The test microorganisms including four pathogenic bacterial species E.coli ,P.aeruginosa, S.aureus and Morganella sp. and two fungal speciesC.albicansandC.glabrata were used to assay the antimicrobial activity of the Actinomycetes isolates. This test was done by perpendicular streaking method on Muller Hinton agar.

Secondary screening of the antimicrobial agent:A well grown agar slant of the isolate was inoculated into $250 \mathrm{ml}$ flaskcontaining $100 \mathrm{ml}$ of the fermentation media, incubated at $28^{\circ} \mathrm{C}$ for 5 days then $10 \mathrm{ml}$ of this culture was transferred to $500 \mathrm{ml}$ of the same medium and the fermentation was carried out at $28^{\circ} \mathrm{C}$ for 5 days. After incubation period the culture broth was collected and filtrated through Whatman No 1. The clear filtrate was divided into three groups, acidic $\mathrm{pH} 3.0$, neutral $\mathrm{pH} 7.0$ and alkaline $\mathrm{pH} 10$. Equal volumes of the filtrate and ethyl acetate as organic solvent were mixed thoroughly by shaking them in $1 \mathrm{~L}$. capacity separating funnel and allowed to stand for $30 \mathrm{~min}$. Two layers were separated; the aqueous layer and the organic layer, which contained the solvent and the antimicrobial agent. The organic layer filtered and was separated and dried over anhydrous $(\mathrm{Na})_{2} \mathrm{SO}_{4}$, then concentrated by evaporation under vacuum to the least volume. The aqueous layer re-extracted and the organic layer added to the above organic layer (Ahmed, 2007). Antimicrobial activity was monitored by the agar well diffusion method. The test organisms diluted with distilled water to give a concentration about (0.5) McFarland, about $0.1 \mathrm{ml}$ of the diluted broth spread on Mueller Hinton agar medium, the wells filled with $200 \mu \mathrm{l}$ crude antimicrobial agent and incubated for $24 \mathrm{~h}$ at $37^{\circ} \mathrm{C}$ to evaluate the inhibition zone diameter (Atta, 2010). 


\section{Results and Discussion:}

Actinomycetes are the main group of soil microorganisms that play a major role in recycling of organic matters in environment by production of hydrolytic enzymes (Mohan and Vijayakumar ,2007).Sixty sevenActinomycetes isolates were isolated from 40 different agriculture soil samples in Hillah city(Table.1). Serial dilutions method and sub- cultured on ISP-2 media was done in order to get isolated colonies ,then stored in refrigerator at $4 \mathrm{o} \mathrm{C}$ for next tests .These isolates were identified according to their morphological features and biochemical tests.The results showed that all of these isolates return to Streptomyces species, they were gave the following characteristic symbols: SA.2 ,SK.5, SM.42, SS.50 and SI.63.(Table.2 ; Figure .1).These isolates were tested for their ability to produce four hydrolyzingenzymes (amylase ,cellulose , protease and L-asparaginase ), in addition to their antimicrobial activity. All Streptomyces isolates were cultured on starch agar media for five days ,then it tested for their ability to produce amylase enzyme by immersing the plates with iodine solution. The appearance of clear zonearound the colonies surrounded by purple color background refer to positive result . Four of these isolates (SA.2 ,SK.5, SM.42, and SI.63) were positive, while SS.50 failed to produce amylase(Figure.2; Table.3) .

There are two isolates were found to be positive for protease production which wereSK.5 and SM.42 when formed clear zone around producing colonies that grown on skim milk, but SA.2, SS.50 and SI.63 were negative(Figure.3) .

For cellulose production test; the isolates were cultured on carboxy methylcellulose media for five days , then plates were flooded by mercuric iodine. The formation of pale color zone around colonies means positive result; the isolates SK.5, SM.42 and SI.63 were positive, while SA.2 and SS.50 were negative(Table.3) .

The single isolate that produce L-aspariginase was SM.42 when grown on ISP-6 media mixed with phenol red. It turned the yellow color of media to pink in color which indicate positive result, while the rest isolates gave negative result(Table. 3 ).

Among soil microorganisms, Actinomycetes considered as an important group of filamentous gram positive bacteria producing many types of antibiotics of medical and agriculture importance .Sterptomycesspp.responsible of $80 \%$ of total common antibiotics(Berdy ,2005). At the present study ,the antimicrobial activity of different Streptomyces isolates were tested .The results exhibited that all tested isolates possess such activity towards most of the tested pathogenic bacteria , while only Streptomyces SS.50 have potential activity against Candida albicans in front of no activity towards Candida glabrata(Table.4 ; Figure 4) .Kavithaet al., isolated four different strains (A1,A2,A3and A4) from the laterite soil samples , and they found that Streptomyces sp.A1 have antifungal activity against Candida albicansandFusariumoxysporum, but it have no activity towards AspergillusnigerandAspergillusflavus.

Table (1): Collection sites of Streptomycesisolates

\begin{tabular}{|c|c|c|}
\multicolumn{2}{c}{ No. of Isolates } & \multicolumn{2}{c}{ Symbol } & Collection site \\
\hline 1 & SA.2 & Annana \\
\hline 2 & SK.5 & Karama \\
\hline 3 & SM.42 & Al-Mahanawia \\
\hline 4 & SS.50 & Sinjar \\
\hline 5 & SI.63 & Al \\
\hline
\end{tabular}

Table (2): Morphological characteristics and biochemical tests of Streptomyces isolates

\begin{tabular}{|c|c|c|c|c|c|}
\hline \multirow[t]{2}{*}{ Test } & \multicolumn{5}{|c|}{ Actinomycetes isolates } \\
\hline & SA.2 & SK.5 & SM.42 & SS.50 & SI.63 \\
\hline Color of aerial mycelium & $\begin{array}{l}\text { pPale } \\
\text { grayp }\end{array}$ & yellow & GGreen & PGray & Pale yellow \\
\hline Color of substrate mycelium & Yellow & Brown & YWhite & Yellow & Brown \\
\hline D-Glucose & + & + & + & + & + \\
\hline Arabinose & + & + & _ & + & + \\
\hline Raffinose & _ & - & - & - & - \\
\hline Fructose & + & + & - & + & + \\
\hline Sucrose & + & _ & + & _ & + \\
\hline Xylose & + & + & + & - & + \\
\hline Mannitole & + & + & - & - & - \\
\hline Inositole & + & - & _- & - & + \\
\hline Diffusible pigments & - & - & - & + & - \\
\hline
\end{tabular}


Table (3) : Enzymatic production ability of Streptomyces isolates

\begin{tabular}{|r|r|r|r|r|r|}
\hline Test & \multicolumn{5}{|r|}{ Samples } \\
\cline { 2 - 6 } & SA.2 & SK.5 & SM.42 & SS.50 & SI.63 \\
\hline Amylase & + & + & + & + & - \\
\hline Protease & - & + & + & - & - \\
\hline Cellulase & - & + & + & - & - \\
\hline L- asparaginase & - & - & + & - \\
\hline
\end{tabular}

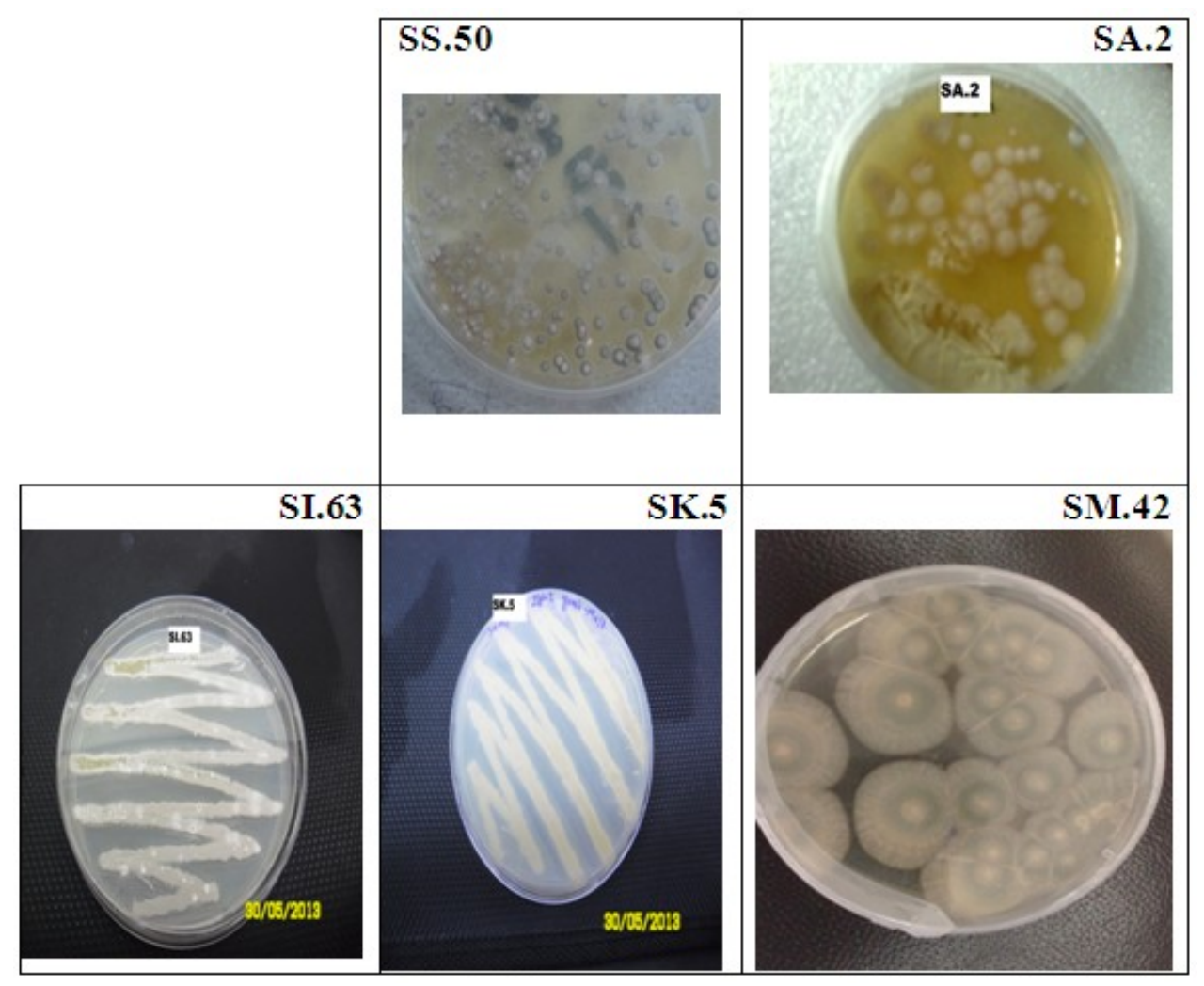

Figure(1):Phenotypic properties of Streptomyces isolates grown on ISP-2 media
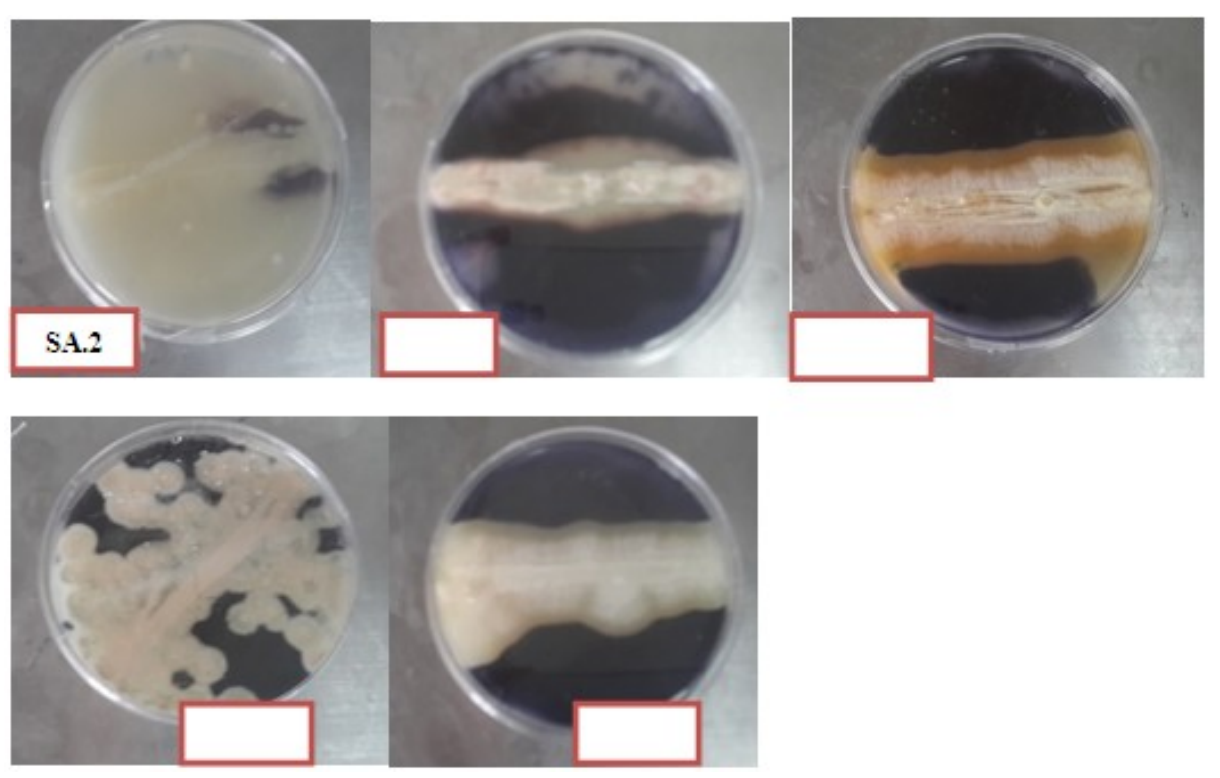

Figure ( 2): Amylase production ability of Streptomycesisolates 

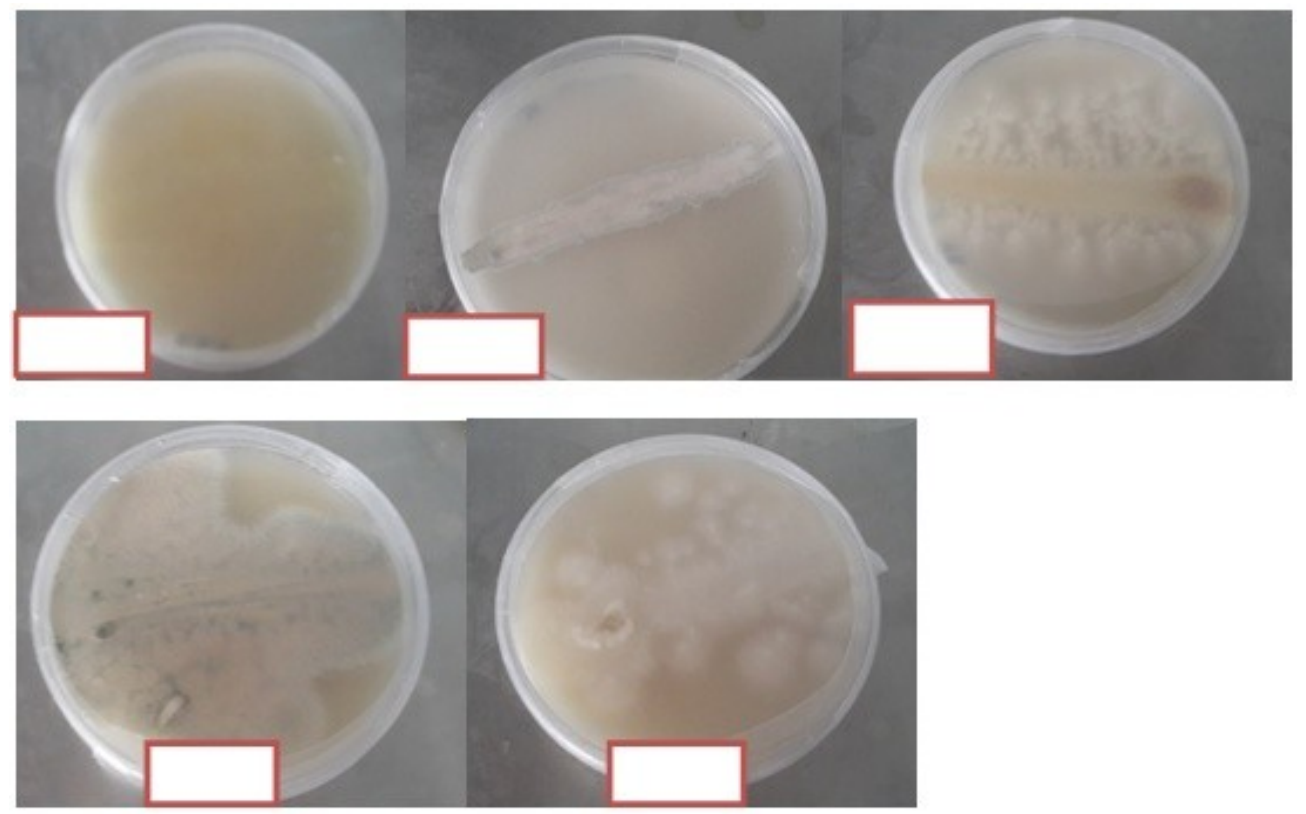

Figure (3): Protease production abilityofStreptomyces isolates

Table (4): Mean of inhibition zone diameter $(\mathrm{mm})$ of culture filtrate extract of the active isolates against tested organisms on Mueller Hinton agar medium.

\begin{tabular}{|c|c|c|c|c|c|}
\hline TEST ORGANISMS & \multicolumn{5}{|c|}{ Inhibition zone (mm) } \\
\hline BACTERIA & SA.2 & SK.5 & SM.42 & SS.50 & SI.63 \\
\hline E. coli & 15 & 16 & 13 & 19 & 14 \\
\hline S. aureus & 17 & 12 & 13 & 18 & 17 \\
\hline P. aeruginosa & 14 & 13 & 15 & 16 & 14 \\
\hline Morganella sp. & 12 & 16 & 13 & 14 & 12 \\
\hline K. pneumonia & 10 & 15 & 13 & 16 & 11 \\
\hline \multicolumn{6}{|l|}{ FANGI } \\
\hline C.albicans & 15 & 11 & 10 & 16 & 15 \\
\hline C.glabrata & 12 & 10 & 12 & 12 & 12 \\
\hline
\end{tabular}

A

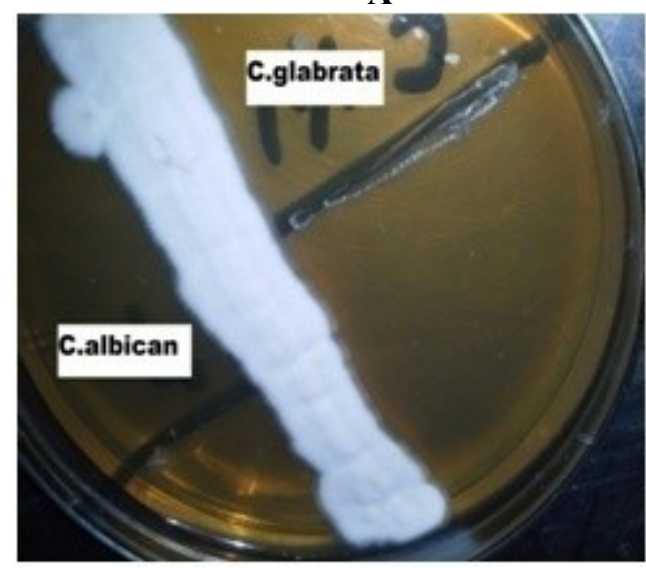

B

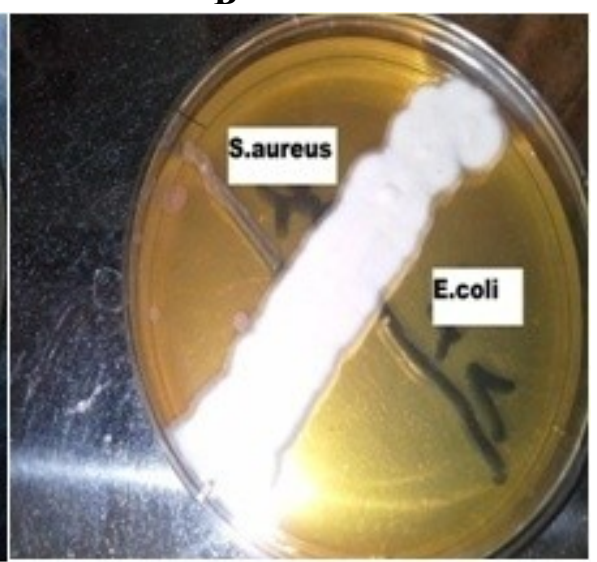

Figure (4): Perpendicular streaking method of Streptomyces SS.50 against C.albicansandC.glabrata (A) ;E.coliandS.aureus (B)

In previous study ,Jarallah(2014) isolated StreptomycesKLG13 from agricultural soil in Hillah city that possess high antibacterial activity against E.coli , P.aeruginosa, S.aureusandMorganellasp.Moreover, another 
study at the same field ,Al-Sadi ,et al.,(2013) isolated tow antibacterial active Actinomycetes from different soil samples of Hillah city coded asS.A.2 and S.S.10 that produce antibiotics work against several types of pathogenic bacteria.

\section{References}

[1]. Ahmed, A. A. (2007). Production of antimicrobial agent by Streptomyces violachromogenes. Saudi J. Bio. Sci. 14: 7-16.

[2]. Al-Saadi,A. N.M.Hameed, E. M. Jaralla .(2013).Isolation andIdentification of Streptomyces from DifferentSample of Soils.Journal of Biology and Medical Sciences - JBMS.1:31-36.

[3]. Atta, H.M.(2010). Production, Purification, Physico - Chemical Characteristics and Biological Activities of Antifungal AntibioticProduced by Streptomycesantibioticus, AZZ710. American- Eurasian J. of Sci. Res.5: 39-49.

[4]. Avitha, A. ;Prabhakar, P. ; Vijayalakshmi, M. and Venkateswarlu, Y. (2010). Purification and biological evaluation of the metabolites produced by Streptomyces sp. TK-VL_333.Res Microbiol.161: 335-345.

[5]. Barros, R.R.O. ; Oliveira, R.A. ; Gottschalk, L.M.F. and Bon, E.P.S. (2010). Production of cellulolytic enzymes by fungi AcrophialophoranainianaandCeratocystisparadoxausing different carbon sources. Appl. Biochem. Biotechnol.161: 448-454.

[6]. Balamurugan, A.; Jayanthi, R.; Nepolean, P.; Vidhya, P.R. and Premkumar, R. (2011). Studies on cellulose degrading bacteria in tea garden soils.Afr. J. Plant Sci. 5 (1) : 22-27.

[7]. Bredy,J.(2005).Bioactive microbial metabolites.J.Antibiot.58:1-26.

[8]. Chiani, M.; Akbarzadeh, A.; Farhangi, A. ;Mazinani, M.; Saffari, Z. ; Emadzadeh, K.andMehrabi, M.R. (2010). Optimization of culture medium to increase the production of desferrioxamine B (desferal) in Streptomyces pilosus.Pak. J. Biol. Sci. 13: 546-550.

[9]. Collins ,C.H.,P.M.Lyne and J.M.Granje. 1995.MicrobiologicalMethod.Butterworth and Heinemann Puplishers ,London.PP:129131.

[10]. Deng, A. ;Wua, J. ; Zhang, Y. ; Zhang, G. and Wena, T. (2010). Purification and characterization of a surfactant-stable highalkaline protease from Bacillus sp. B001.Bioresource Technol. 101: 7100-7106.

[11]. Gulve, R.M. and Deshmukh, A.M. (2012). Antimicrobial activity of the marine Actinomycetes. Inter. Multidiscipl. Res. J. 2(3):1622.

[12]. Ibrahim, A.S.S. (2007).Isolation and identification of new cellulase producing thermophilic bacteria from an Egyptian hot spring and some properties of the crude enzyme.Aust. J. Basic Appl. Sci. 1: 473-478.

[13]. Jarallah,I .M.(2014). Screening for Antimicrobial Agents Producing Actinomycetes Isolated from Agricultural Soils in Hilla/Iraq.IOSRJournal.Vol.9( 2) :47-52.

[14]. Kafitha , A.,M.Vijayalakshmi ,P.Sudhakar and G.Narasimha.(2010).Screening of Actinomycetes strains for the production of antifungal metabolites. African J.Microbiol.Res.Vol.4(1) : 27-32.

[15]. Kar, S. and Ray, R. C. (2008). Statistical optimization of alpha amylase production by Streptomyces erumpens MTCC 7317 cells in calcium alginate beads using response surface methodology. Polish J. Microbiol.57: 49-57.

[16]. Kavya ,M. , M. Solomon and N. Devamma .(2012).Isolation and screening of Streptomycetes sp. from Coringa Mangrove for enzyme production and antimicrobial activity.Inter.J.Pharmceut.Chemical\&Biological Sciences.2(1):110-116.

[17]. Khamna, S. ; Yokota ,A. and Lumyong, S. (2009). L-Asparaginase production by actinomycetes isolated from some Thai medicinal plant rhizosphere soils. Int. J. Integr. Biol. 6(1): 22-26.

[18]. Kumar, M.S. and Selvam, K. (2011).Isolation and purification of high efficiency L-asparaginase by quantitative preparative continuous elution SDS PAGE electrophoresis.J. Microb. Biochem. Technol.3(5): 073-083.

[19]. Kuhad, R.C., R. ; Gupta, and Singh, A. (2011). Microbial cellulases and their industrial applications. Enzyme Res. 1-10.

[20]. Limkhada, J.R. ; Mander, P. ; Cho, S.S. and Yoo, J.C. (2010). A novel fibrinolytic protease from Streptomyces sp. CS684.ProcBiochem. 45: 88-93.

[21]. Mohan ,R. and R. Vijayakumar (2007).Isolation and characterization of marine antagonistic actinomycetes from west coast of India. Medcine\&Biology .15(1):13-19.

[22]. Pridham, T. G. andTresner, R. D. (1975). Family VU.StreptomycetaceaeWaksman and Henrici 1943, 339.fu: RE Buchanan and NE Gibson (eds). Bergey's Manual od Determinative Bacteriology. $8^{\text {th }}$ ed :747-845. Williams and Wilkins, Baltimore, Maryland.

[23]. Ribitscha, D. ; Karla, W. ; Birner-Gruenbergera, R. ; Grubera, K. ; Eiteljoerg, I. ; Remlera, P. et al. (2010). C-terminal truncation of a metagenome-derived detergent protease for effective expression in E. coli.J Biotech.150: 408-416.

[24]. Savitri, N.A. and Azmi, W. (2003). Microbial L-asparaginase: A potent antitumour enzyme. Ind. J. Biotechnol.2: $184-194$.

[25]. Tonkova, A. (2006). Microbial starch converting enzymes of the amylase family, In: Ray, C.R. and O.P. words. Mirobial biotech.Horticult.1: $421-472$. 